\title{
23. DETAILED RECORD OF THE BRUNHES/MATUYAMA POLARITY REVERSAL IN HIGH SEDIMENTATION RATE MARINE SEDIMENTS FROM THE IZU-BONIN ARC ${ }^{1}$
}

\author{
Stanley M. Cisowski² and Masato Koyama ${ }^{3}$
}

\begin{abstract}
A combination of high sedimentation rates and high concentrations of magnetic grains in cores from Ocean Drilling Program Leg 126 resulted in the recovery of detailed direction and intensity records of the Brunhes/Matuyama geomagnetic polarity reversal. Virtual geomagnetic poles (VGPs) computed from azimuthally oriented samples taken from the cores of Hole 792A in the western Izu-Bonin forearc basin reveal that the geomagnetic pole persisted at moderate to high southern latitudes for several thousand years before a rapid migration to northern latitudes. Alternating-field demagnetization behavior, as well as NRM, NRM/ARM, and NRM/IRM intensities for samples from this same interval, and the NRM/IRM intensities derived from unoriented core samples from Holes 790C and 791B, drilled in the $~ 100-\mathrm{km}$ distant Sumisu Rift, all suggest that the dipole field oscillated widely in intensity before the reversal. The fast polarity change occurred at the low point of an $\sim 1100$-yr field intensity cycle. This "reversal cycle" immediately followed earlier intensity cycles whose peaks rivaled or surpassed the normalized intensities of discrete samples from well above and below the reversal interval; furthermore, the troughs indicate a much diminished dipole field at their nadir.
\end{abstract}

\section{INTRODUCTION}

Rocks that acquired their remanent magnetizations during the Earth's reversals of geomagnetic field polarity represent our best opportunity to decipher the physics of the geomagnetic reversal process. Therefore, they can help to improve our understanding of the actual mechanisms of field generation that operate in the Earth's core. However, records of field behavior during polarity transitions are often lacking in detail, either because of low sedimentation rates and time averaging of remanence acquisition, or because of weak intensity of the primary component of magnetization, which inhibits the standard paleomagnetic "cleaning" techniques used to improve the "signalto-noise" ratio.

A fortuitous combination of high sedimentation rates and moderately strong magnetic remanence intensities $\left(10^{-5}-10^{-6} \mathrm{kA} / \mathrm{m}\right)$, attributable to a volcanic arc sedimentary environment, allowed us to recover a number of highly detailed records for the Brunhes/Matuyama polarity transition in the Izu-Bonin volcanic arc region. Recovery of lightly bioturbated and moderately deformed clays that were magnetized during this most recent reversal of the geomagnetic field occurred in Holes 790C, 791B, and 792A. The intervals of clay that include the polarity transition have estimated sediment accumulation rates of 90,300 , and $81 \mathrm{~m} / \mathrm{m}$.y. respectively, as based on paleomagnetic and biostratigraphic datums distributed over $\sim 500,000$ yr (Taylor, Fujioka, et al., 1990, "Sites 790/791" chapter, fig. 40, and "Site 792" chapter, fig. 28). Of these three records, only individual samples and piston core sections from Hole 792A were oriented azimuthally with the multishot tool; however, an approximate orientation was derived for certain discrete samples from Hole 791B, which displayed highly dipping $\left(20^{\circ}-45^{\circ}\right)$ bedding planes in comparison with the regional dip direction observed in the seismic profiles (Taylor, Fujioka, et al., 1990, "Sites 790/791" chapter, fig. 53). Unfortunately, the limited number of samples in which the bedding planes were visible did not allow us to develop of a detailed directional reversal record from Hole 791B.

\footnotetext{
${ }^{1}$ Taylor, B., Fujioka, K., et al., 1992. Proc. ODP, Sci. Results, 126: College Station, TX (Ocean Drilling Program).

${ }^{2}$ Department of Geological Sciences, University of California at Santa Barbara, Santa Barbara, CA 93106 , U.S.A.

${ }^{3}$ Faculty of Education, Shizuoka University, 836 Oya, Shizuoka 422, Japan.
}

\section{PROCEDURES}

Archive halves of the core sections that included the transitional field record were measured on board ship with the automated $2 \mathrm{G}$ cryogenic pass-through magnetometer, as is standard procedure for all ODP sediment cores. The core sections were measured at $0.5-\mathrm{cm}$ intervals both before and after alternating-field (AF) demagnetization to $15 \mathrm{mT}$, which is the minimal pass-through measurement interval possible and maximum core demagnetization permissible under current ODP policy. Numerous $7-\mathrm{cm}^{3}$ discrete samples, representing $2 \mathrm{~cm}$ of core depth, were taken near the centers of the sampling halves at various points above, across, and below the three reversal intervals sampled, to allow for a more detailed rendering of the reversal record. These samples were measured and demagnetized either on the FAS spinner magnetometer with built-in AF demagnetizing coils, available on board the ship only for this leg (see Taylor, Fujioka, et al., 1990, "Explanatory Notes" chapter), or with a Molspin spinner magnetometer and $2 \mathrm{G}$ cryogenic magnetometer, and static specimen AF demagnetizer, at Santa Barbara. The discrete samples were subjected to stepwise AF demagnetization to as high as $100 \mathrm{mT}$, and in some cases, subsequent thermal demagnetization; in addition, frequent measurements were made on the cryogenic magnetometer with the samples still at high temperatures. This procedure, which we refer to as continuous thermal demagnetization, often allows a better determination of the primary direction of magnetization than conventional stepwise thermal demagnetization with measurements taken at room temperature because it avoids the problems of alteration and interactions between phases with differing blocking temperatures, which can occur on cooling.

Following AF demagnetization of NRM, the samples were subjected to anhysteretic remanent magnetization (ARM) acquisition by applying a $100-\mathrm{mT}$ alternating field in the presence of a $0.1-\mathrm{mT}$ DC field, as well as isothermal remanent magnetization (IRM) acquisition by applying a $600-\mathrm{mT}$ DC field. Both types of remanence were measured to determine the relative amounts of remanence carriers in each sample, and so to derive normalization parameters for detecting changes in relative paleointensity. $\mathrm{A}<5 \%$ increase in IRM acquired after 600 -mT field exposure, as compared with IRM acquired at $300 \mathrm{mT}$, indicated that fine-grained hematite was not a substantial contributor to remanence in any of the samples, and that the $600-\mathrm{mT}$ IRM was a close approximation to saturation remanence for these samples. Following laboratory remanence acquisition, the samples were subjected to demagnetization at various $\mathrm{AF}$ levels. A few se- 
lected samples were subjected to more detailed stepwise IRM and ARM acquisition and demagnetization procedures in order to obtain information about their coercivity spectra.

\section{RESULTS}

\section{Directional Behavior}

The pass-through record of the archive-half measurements made onboard ship indicated that multiple changes of the inclination sign occurred in each of the reversal core sections (Fig. 1A; Taylor, Fujioka, et al., "Sites 790/791" chapter, fig. 50, and "Site 792" chapter, fig. 40). However, more extensive onshore AF and thermal demagnetization of discrete samples from the bottom-most positive inclination interval indicated that all of the samples from this zone possessed a primary component with a negative inclination. For Hole $792 \mathrm{~A}$ samples from immediately below the change from negative to positive inclination at $\sim 6 \mathrm{~cm}(58.16 \mathrm{mbsf})$ in Core $126-792 \mathrm{~A}-7 \mathrm{H}-2$ (Fig. 1A), AF demagnetization at low fields was sufficient to reveal the reversed primary component of magnetization (Fig. 2). But for samples from the apparent normal polarity interval (from 15 to $31 \mathrm{~cm}$ in Fig. 1A), a combination of AF demagnetization and continuous



B.

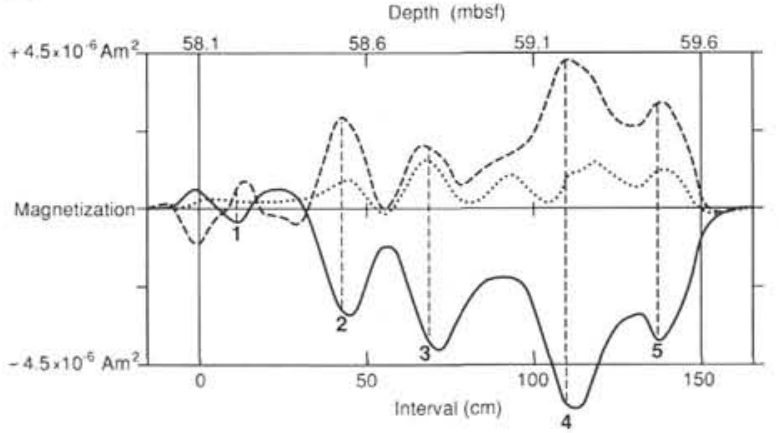

Figure 1. A. Declination (D), inclination (I), and intensity measurements of the archive half-core section of Core 126-792A-7H-2, after AF demagnetization to $15 \mathrm{mT}$. The top of the core section was at $58.10 \mathrm{mbsf}$. Small dots (Numbers 1-14, see Fig. 5) indicate the positions, inclinations, and declinations (after optimum demagnetization) of discrete samples measured for this study. The intensity plateau between intensity Peaks 1 and 2 corresponds to a zone of incomplete removal of present field (normal) overprint. B. Intensity plot of the $\mathrm{X}$ (dotted line), $\mathrm{Y}$ (dashed line), and $\mathrm{Z}$ (solid line) components of magnetization for the same core section. Negative $\mathrm{Z}$ values correspond to zones of negative inclination (reversed polarity). Intensities have not been deconvolved with the response function of the cryogenic magnetometer. thermal demagnetization was required to reveal the reversed primary component (Figs. 3A and 3B). Similar resistant behavior occurred for Hole 790C samples from the same "normal" polarity interval. However for the Hole 791B samples in this same zone, AF demagnetization in fields of only moderate strength was sufficient to recover the primary reversed component. In contrast to the samples from below the reversal horizon at $6 \mathrm{~cm}$ (Fig. 1A), the inclinations of Hole 792A samples taken from immediately above the true reversal horizon remained positive with thermal demagnetization to $590^{\circ} \mathrm{C}$.

Discrete samples from a higher reversed inclination zone (interval A, Taylor, Fujioka, et al., 1990, "Site 792" chapter, fig. 40A), which exactly corresponds to a disturbed silty to sandy volcanic ash layer in overlying Section 126-792A-7H-1 (Fig. 4), displayed unstable and scattered directional behavior upon $\mathrm{AF}$ demagnetization. This result indicates that the magnetization of this part of the core is not representative of the field polarity during its time of deposition.

Figure 5 represents the virtual geomagnetic pole (VGP) path derived from the Hole $792 \mathrm{~A}$ discrete sample measurements. The VGPs chosen for each sampled interval correspond to stable directions achieved after AF or a combination of $\mathrm{AF}$ and thermal demagnetization. Table 1 lists the locations of the discrete samples included in the VGP path figure and gives the demagnetization value employed to achieve the plotted VGP.

The VGP plot indicates that the apparent pole was confined from moderate to high southern latitudes $\left(>45^{\circ}\right)$ for a $1-\mathrm{m}$ zone immediately below the polarity reversal. Within this interval, which corresponds to $\sim 12,000 \mathrm{yr}$ if the estimated average sedimentation rate applies here, two clockwise loops enclosing a small counterclockwise loop, are discernable. The first of the clockwise loops is tightly centered on the southeast Indian Ocean, whereas the second is more loosely centered on the geographic South Pole. The subsequent migration of the VGP from the Southern to the Northern Hemisphere is exceedingly rapid, occurring within the vertical interval between Samples 126-792A-7H-2, 4.7-6.7 and 7-9 cm of $~ 3 \mathrm{~mm}$ (a nominal $37 \mathrm{yr}$ ) whereas migration from $\sim 58^{\circ} \mathrm{S}$ to $\sim 65^{\circ} \mathrm{N}$ latitude encompasses $\sim 9 \mathrm{~cm}$, or a nominal $1100 \mathrm{yr}$, based on the average sedimentation rate. Resolution of the VGP path after the polarity reversal is complete is complicated by the lack of reliable VGPs from the disturbed sandy ashy interval, and by a 4-cm interval at the top of Section 126-792A$7 \mathrm{H}-2$ that was heavily sampled by other investigators.

\section{Intensity of Remanent Magnetization}

The intensity of NRM after demagnetization varies by nearly a factor of 30 for the discrete samples taken over the $\sim 2-\mathrm{m}$ Hole $792 \mathrm{~A}$ sampling interval that includes the Brunhes/Matuyama reversal (Table 1). In general, these variations correspond to the oscillations of intensity that precede the inclination polarity change for the archive half pass-through measurements (Figs. 1A and 1B). To test whether these intensity variations represent actual changes in the strength of the geomagnetic field at that time, each discrete sample was subjected to ARM and high-field IRM acquisition. Normalization of NRM to laboratory-induced remanence can reveal relative changes in paleofield intensity, providing that the concentration, composition, and grain size of the remanence carriers over the sampling interval are fairly uniform (King et al., 1983).

Because AF demagnetization was essential to isolate the primary component of magnetization in most of the samples from below the reversal horizon, only NRM values after demagnetization to 20 or $25 \mathrm{mT}$ $\left(\mathrm{NRM}^{\prime}\right.$ in Table 1) were used for normalization. Samples from the intervals which required thermal demagnetization for isolation of the primary reversed component (e.g., Sample 126-792A-7H-2-15, Fig. 3B) were not included, as heating to $600^{\circ} \mathrm{C}$ produced irreversible changes in the remanence properties of the samples. We also employed demagnetized ARM and IRM intensities so as to eliminate fully the contributions of low coercivity carriers from the normalization record. Computation of 



Figure 2. Response of field vector, VGP, orthogonal components, and normalized intensity of Sample 126-792A-7H-2, 9-11 cm, to AF demagnetization. + = positive (lower hemisphere) inclination and Northern Hemisphere VGP. Solid circle $=$ negative (lower hemisphere) inclination and Southern Hemisphere VGP. Large solid circle $=$ VGP direction before demagnetization. Unconnected plus signs in the field plot indicate the directions of vectors removed in the first two $(5$ and $10 \mathrm{mT})$ demagnetization steps. Solid square indicates present field direction for Site 792.

the $\mathrm{NRM}^{\prime} / \mathrm{IRM}$ ' ratio for 50 normal samples taken from above the Brunhes/Matuyama reversal at Sites 790-793 indicate a distribution about a peak value of $\sim 0.002$ (Fig. 6A). Figure 6B illustrates that the reversal interval clearly represents a period of anomalous intensity, as the median NRM/IRM value for samples from the interval falls below the range of 17 randomly selected normal samples representing deposition over the past $700,000 \mathrm{yr}$.

Table 1 lists these normalized intensity values after demagnetization for samples from Sections 126-792A-7H-1 and -2 (NRM'/IRM'). Figure 7A illustrates the variation of the NRM'/IRM' ratio with depth for the reversal interval in Holes 790C and 791B, whereas Figure 7B shows both the NRM'/ARM' and NRM'/IRM' ratios for Hole 792A. Depths for the Hole 790C samples were from their distance from the reversal horizon, after correcting for the variation in the estimated sediment accumulation rates for Holes 790C and 791B. Only a few data points could be derived for Hole $790 \mathrm{C}$ because of our extensive use of thermal demagnetization for its samples. Note that the $\sim 4.4-\mathrm{m}$ gap before the last six data points for Hole 791B results from the incomplete $(<60 \%)$ recovery in this (126-791B-39R) and the overlying core.

Figure 7C compares the variation of VGP latitude with depth to the normalized NRM data for Hole 792A. The generally shallower latitudes displayed by the reversed samples is probably caused in large part by the incomplete removal of the viscous normal component by demagnetization. Note that the use of a standard demagnetization treatment (e.g., $25-\mathrm{mT} \mathrm{AF}$ as represented by the small triangles), rather than optimal thermal and/or AF treatment, produces a pole path with multiple crossings of the equator and additional low latitude points.

Figure 7B clearly shows that the oscillations present in the demagnetized NRM data persist after normalization to either ARM or high field IRM. We have numbered the peaks in normalized intensity as an aid in comparing the discrete sample intensities with the archive half pass-through measurements. The closely spaced peaks in Figure 7B (\#1 a and \#1b), which occur immediately below the first sample with normal VGP polarity, correspond in depth to the single subdued peak labeled \#1 in Figure 1. The absence of two peaks in the archive half measurement results from the smoothing effect of the passthrough cryogenic magnetometer measurement, which has broad $(\sim 20 \mathrm{~cm})$ sensor response curves for all three measurement axes. The trough in intensity immediately below these peaks corresponds to the zone of normal inclinations present between 16 and $21 \mathrm{~cm}$ in Figure 1 (Taylor, Fujioka, et al., 1990, "Site 792" chapter, interval D in fig. 40A). As described above, discrete samples from this region reveal their primary reversed component of remanence only after AF demagnetization to high fields or thermal demagnetization. This trough is preceded by two more cycles in normalized intensity, again congruent in depth with the pass-through intensity profile. The bottom-most sample $(126-792 \mathrm{~A}-7-2,110 \mathrm{~cm})$, which is situated near Peak \#4 in Figure 1, displays an NRM'/IRM' value of 0.001 , which is near the median of the post-reversal samples of this leg (Fig. 6).

The periods of the intensity cycles apparent in Figures 1 and 7B range from $\sim 1100$ to $\sim 5000 \mathrm{yr}$, as calculated from the estimated 

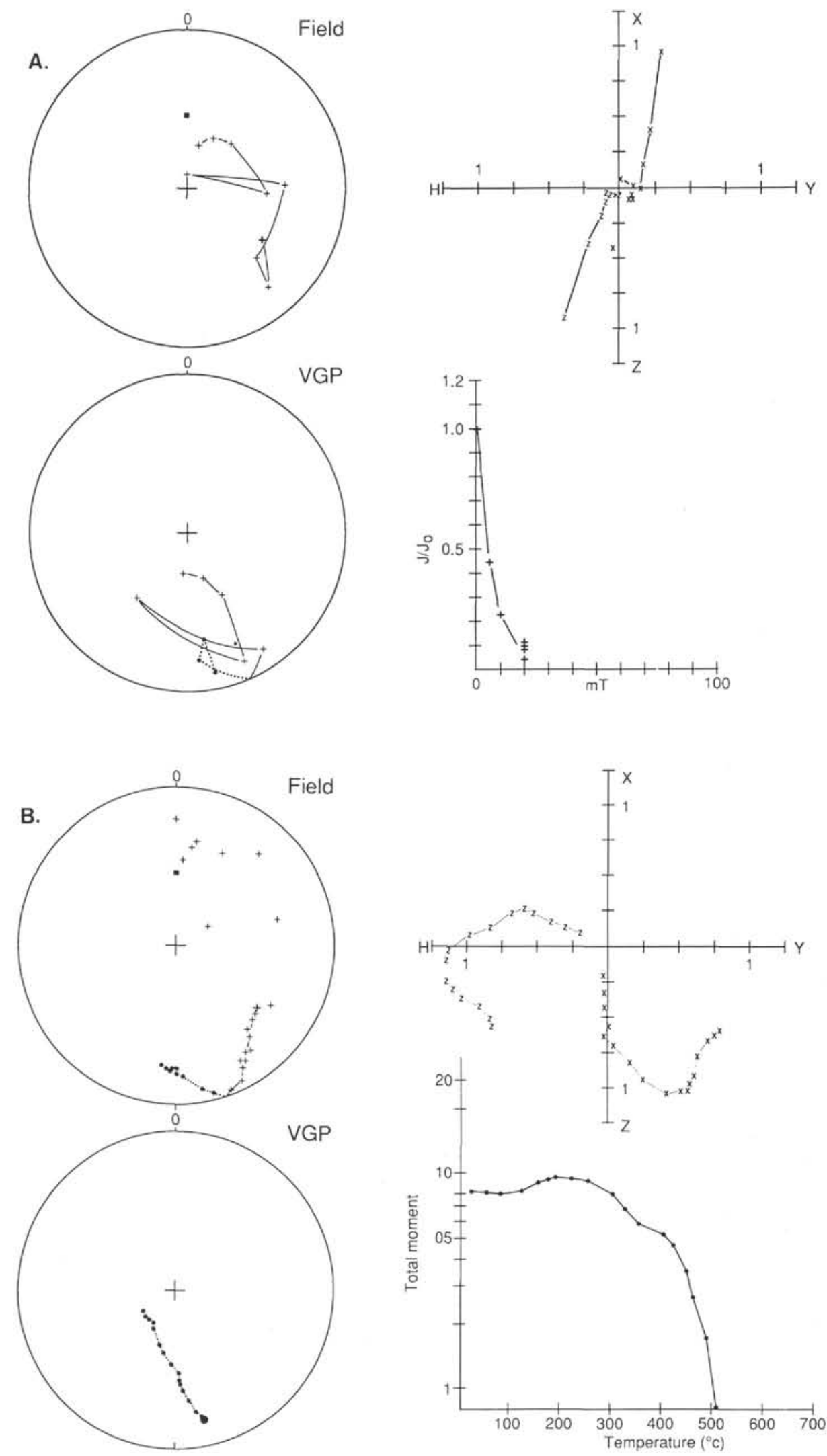

Figure 3. A. Same as Figure 2, for Sample 126-792A-7H-2, 15-17 cm. B. Response of sample to continuous thermal demagnetization. 


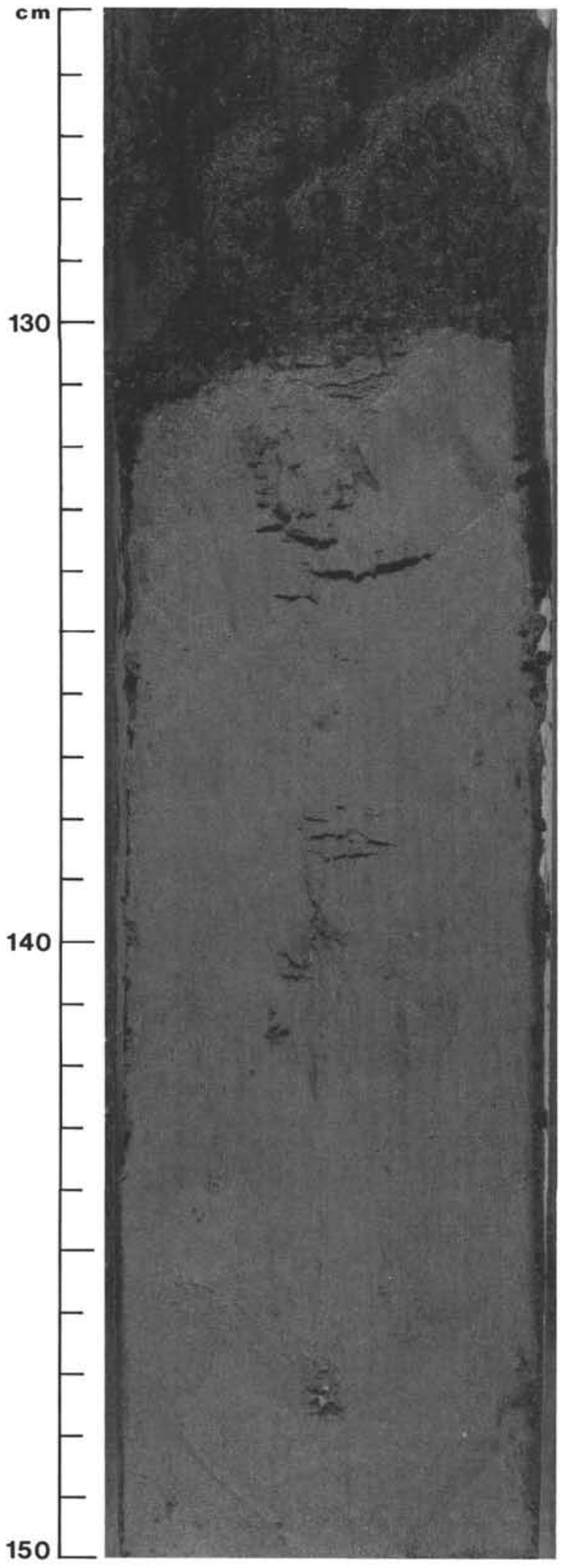

Figure 4. Core photograph of a portion of Section 126-792A-7H-1, 125-150 $\mathrm{cm}$, showing the bottom of the highly disturbed, silty to sandy ash layer.

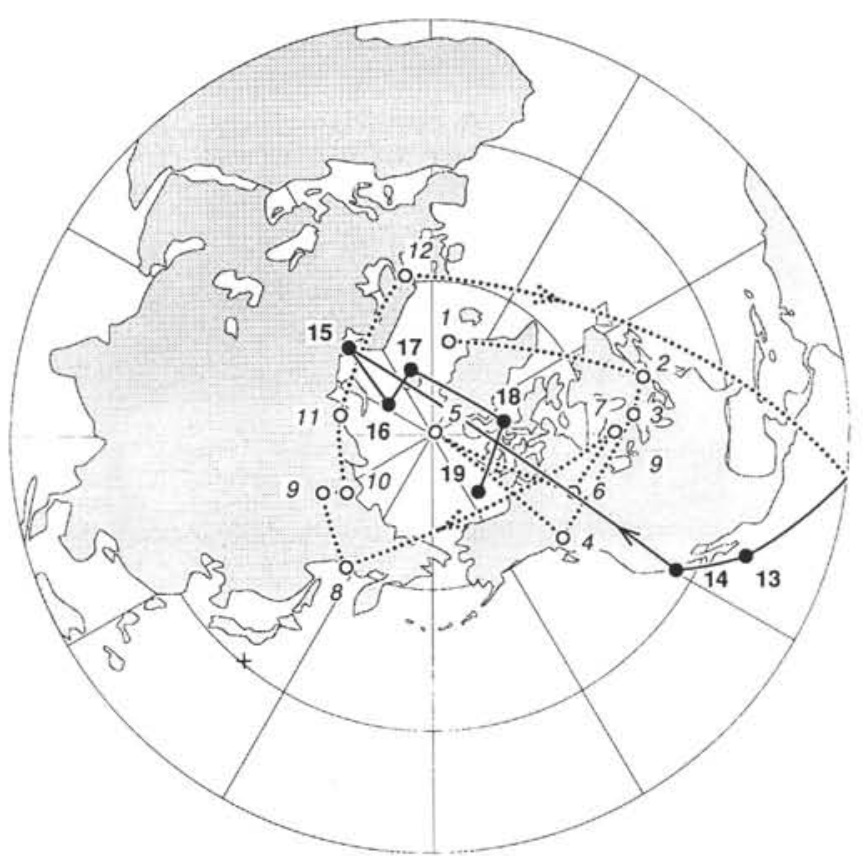

Figure 5. VGP plot for Brunhes/Matuyama reversal, as recorded in Sections 126-792A-7H-1 and -2. Open circles indicate Southern Hemisphere (reversed) pole. Solid circles indicate Northern Hemisphere (normal) poles. Plotted points correspond to samples listed in Table 1, with Number 1 point corresponding to the lowermost (reversed) sample. Plus sign $=$ sampling site.

average sedimentation rate of $81 \mathrm{~m} / \mathrm{m}$.y. for this portion of Hole $792 \mathrm{~A}$, with the shortest cycles occurring in the vicinity of the reversal horizon. The intensity cycle that brackets the VGP polarity change, starting with Peak \#1a in Figure 7B, occurs over $\sim 9 \mathrm{~cm}(\sim 1100 \mathrm{yr})$. It is within this intensity cycle that the VGP migrates from $\sim 60^{\circ} \mathrm{S}$ to $\sim 60^{\circ} \mathrm{N}$ latitude (Fig. 7C). The total length of anomalous intensity behavior that encompasses the polarity reversal equals $\sim 2 \mathrm{~m}$ (Taylor, Fujioka, et al., 1990 "Site 792" chapter, fig. 40A) or $\sim 25,000$ yr, with the most extreme fluctuations in normalized intensity occurring over $0.8 \mathrm{~m}$, or $\sim 10,000 \mathrm{yr}$.

Similar calculations for the extent of the high variation period for Holes 790C and 791B (Fig. 7A; Taylor, Fujioka, et al., 1990, "Sites $790 / 791$ " chapter, fig. 50) yield estimates of $11,000 \mathrm{yr}$ and 6,700 yr, respectively. However, these two core records are complicated by the positions of their reversal planes near the bottoms of the cores, and by incomplete recoveries. In Hole 791B most cores had recovery rates of $<50 \%$, which could result to a significant overestimation of the true sediment accumulation rate, particularly if the unrecovered material represented rapidly deposited sediment.

\section{DISCUSSION}

A number of interesting features characterize the Brunhes/Matuyama reversal records obtained from the Leg 126 cores. First among these is the apparent extremely rapid migration of the VGP from the Southern to the Northern Hemisphere. In a further search for VGP data points with low southern latitudes, a sample (126-792A-7H-2, $5.7-7.7 \mathrm{~cm}$ ) was taken that overlapped both the overlying (126-792A$7 \mathrm{H}-2,4.7-6.7 \mathrm{~cm})$ and underlying $(126-792 \mathrm{~A}-7 \mathrm{H}-2,7-9 \mathrm{~cm}) \mathrm{sam}-$ ples. Although the whole sample exhibited a stable field vector directional behavior that corresponded to a more intermediate VGP latitude of $21.9^{\circ} \mathrm{N}$ (Table 1), attempts to isolate physically a VGP of low southern latitude by measuring only the middle third of the sample failed. Even the progressive scraping off of the top portion of 
Table 1. Remanence properties of samples from Core 126-792A-7H.

\begin{tabular}{|c|c|c|c|c|c|c|c|c|}
\hline $\begin{array}{l}\text { Core, section, } \\
\text { interval }(\mathrm{cm})\end{array}$ & IRM & ARM & $\mathrm{NRM}^{\prime}$ & $\begin{array}{l}\text { NRMé/ } \\
\text { IRM' }^{\prime}\end{array}$ & $\begin{array}{l}\mathrm{NRM}^{\prime} / \\
\mathrm{ARM}^{\prime}\end{array}$ & VGPÉ & $\mathrm{Dm}$ & Ty \\
\hline \multicolumn{9}{|l|}{$126-792 \mathrm{~A}-$} \\
\hline $\begin{array}{l}7 \mathrm{H}-1,62 \\
7 \mathrm{H}-1,77\end{array}$ & $\begin{array}{l}1.61 \mathrm{E}-2 \\
1.56\end{array}$ & $\begin{array}{l}2.95 \mathrm{E}-4 \\
2.61\end{array}$ & $\begin{array}{l}1.53 \mathrm{E}-5 \\
.35\end{array}$ & $1.81 \mathrm{E}-3$ & $6.90 \mathrm{E}-2$ & $\begin{array}{l}\text { N76.5, W137.6 } \\
\text { N75.3, W79.9 }\end{array}$ & $\begin{array}{l}20 \\
20\end{array}$ & 二 \\
\hline $7 \mathrm{H}-1,97$ & 1.24 & 1.86 & 0.28 & 0.35 & 1.89 & N76.9, E18.0 & 20 & - \\
\hline $7 \mathrm{H}-1,139$ & 3.34 & 5.70 & 0.90 & 0.40 & 1.97 & N78.8, E52.6 & 20 & - \\
\hline $7 \mathrm{H}-1,146$ & 3.14 & 5.44 & 1.11 & 0.71 & 2.80 & N65.1, E43.2 & 25 & - \\
\hline $7 \mathrm{H}-2,4.7$ & 2.67 & 5.08 & 0.55 & 0.49 & 1.60 & N32.2, W119.2 & 25 & - \\
\hline $7 \mathrm{H}-2,5.7$ & 2.91 & 6.21 & 0.53 & 0.30 & 0.77 & N21.9, W111.0 & $\begin{array}{c}20 \\
(25)\end{array}$ & - \\
\hline $7 \mathrm{H}-2,7$ & 3.44 & 6.92 & 3.05 & 1.82 & 5.60 & S58.0, E8.4 & 30 & A \\
\hline $7 \mathrm{H}-2,9$ & - & 4.28 & 1.12 & - & 3.45 & S71.2, E78.4 & 50 & A \\
\hline $7 \mathrm{H}-2,15$ & 1.57 & 3.04 & 0.24 & 0.26 & 1.09 & S69.6, E122.3 & $\begin{array}{l}487^{\circ} \\
(25)\end{array}$ & B \\
\hline $7 \mathrm{H}-2,18$ & 0.79 & 1.29 & 0.55 & 1.46 & 6.06 & S67.0, E128.4 & 20 & A \\
\hline $7 \mathrm{H}-2,21$ & ${ }^{a} 1.82$ & 3.22 & 0.23 & ${ }^{\mathrm{a}} 0.19$ & ${ }^{2} 0.96$ & S58.6, E145.4 & $\begin{array}{l}443^{\circ} \\
(25)\end{array}$ & $\mathrm{B}$ \\
\hline $7 \mathrm{H}-2,25$ & 1.27 & 2.57 & 0.11 & 0.20 & 0.56 & S53.7, W89.1 & $\begin{array}{c}60 \\
(25)\end{array}$ & B \\
\hline $7 \mathrm{H}-2,38$ & 0.54 & 1.10 & 0.42 & 1.92 & 5.56 & S59.6, W110.4 & 25 & A \\
\hline $7 \mathrm{H}-2,42$ & 0.17 & 0.49 & 1.00 & 20.30 & 25.60 & S88.6, W25.5 & 25 & A \\
\hline $7 \mathrm{H}-2,52$ & 2.43 & 4.28 & 0.17 & 0.12 & 0.52 & S 56.4, W 129.2 & 25 & B \\
\hline $7 \mathrm{H}-2,69$ & 3.54 & 5.15 & 0.92 & 0.43 & 0.24 & S50.1, W85.6 & 25 & A \\
\hline $7 \mathrm{H}-2,83$ & 2.70 & 4.14 & 0.50 & 0.31 & 1.66 & S46.7, W75.0 & 25 & A \\
\hline $7 \mathrm{H}-2,110$ & 3.75 & 3.78 & 2.47 & $1.0 \mathrm{i}$ & 8.56 & S72.5, W6.5 & $\begin{array}{c}35 \\
(25)\end{array}$ & A \\
\hline
\end{tabular}

Notes: IRM, ARM, and $\mathrm{NRM}^{\prime}$ are in $\mathrm{kA} / \mathrm{m}$. IRM is measured after exposure to a $600-\mathrm{mT}$ field. ARM is measured after exposure to a $0.1-\mathrm{mT}$ field $(100-\mathrm{mT}$ AF). ' indicates intensities and VGPs after AF demagnetization. Dm $=$ demaagnetizing field $(\mathrm{mT})$ or temperature $\left({ }^{\circ} \mathrm{C}\right)$ used to determine VGP. Values in parentheses indicate demagnetizing fields used for $\mathrm{NRM}^{\prime}$, IPM $^{\prime}$, and $\mathrm{ARM}^{\prime}$ values, when different from VGP demagnetization. Ty = type of AF demagnetizing curve for reversed samples (see text).

${ }^{\text {a }}$ Measurements made after heating the sample to $500^{\circ} \mathrm{C}$.

the subdivided sample until it crumbled failed to produce a more southerly VGP. Similarly, separation and measurement of the top third of the underlying sample achieved only a $12^{\circ}$ lowering of the VGP latitude, from $69.8^{\circ} \mathrm{S}$ to $58.0^{\circ} \mathrm{S}$. Apparently, VGP migration across the equator is not resolvable in this hole much beyond what appears in Figure 5.

An obvious caveat to the interpretation of extremely rapid VGP motion (i.e., $>1 \% \mathrm{yr}$ ) is that a sedimentary hiatus corresponds with the reversal horizon recorded in Hole 792A. Although no physical evidence for such a coincidental disruption in sedimentation appears in the core section at this point (Fig. 8), the lack of a low-intensity reversed interval immediately above Peak \#la and below the reversal plane (Fig. 7B), as occurs in Hole 791B (Fig. 7A), could allow for the absence of up to $\sim 6 \mathrm{~cm}(\sim 740 \mathrm{yr})$ of material directly below the apparent reversal horizon.

Uncertainty about the true sedimentation rate for the portion of Hole $792 \mathrm{~A}$ containing the reversal could also result in an overstatement of the polarity reversal rate. However there are a number of indications that this average sedimentation rate, which was computed from a number of biostratigraphic as well as paleomagnetic datums (see Taylor, Fujioka, et al., 1990, "Site 792" chapter, fig. 28), has not been overestimated by more than a factor of 2 within this interval. First, the 10,000-25,000 yr period of anomalous intensity behavior related to the reversal is as long or longer than anomalous intensity periods reported by other reversal studies (Fuller et al., 1979). Second, most of the reversal interval is composed of the same vitric silty clay that makes up most of the interval over which the sediment accumulation rate of $81 \mathrm{~m} / \mathrm{m}$.y. was computed (Taylor, Fujioka, et al., 1990, "Site 792" chapter, table 2). The percent recovery of Core 126-792A$7 \mathrm{H}$ was $79.3 \%$, so that even if the remaining $20.7 \%$ consisted of rapidly deposited ash or turbidity flows, only a $\sim 20 \%$ reduction in sedimentation rate for the clays would be achieved. Also the equivalent lengths of the reversal intervals in Holes 791B and 792A (Figs. $7 \mathrm{~A}$ and $7 \mathrm{~B}$ ) suggests that the sedimentation rate in the Hole 792A may be nearer to the $300-\mathrm{m} / \mathrm{m}$.y. figure associated with Hole $791 \mathrm{~B}$.

Further evidence for the reality of an extremely rapid polarity reversal time frame has been provided from a land-based sedimentary sequence on the Boso Peninsula, Japan, $<300 \mathrm{~km}$ from the Leg 126 sites. From that location, Okada and Niitsuma (1989) have reported an almost identical time span ( $38 \mathrm{yr}$ ) for the equatorial crossing of the pole during the Brunhes/Matuyama reversal, for sediments with an accumulation rate more than an order of magnitude higher than those encountered in our reversal sequences. Okada and Niitsuma (1989) also found that the VGP resided primarily at moderate to high southern latitudes for the several thousand years immediately preceding the rapid inclination sign change, although their intensity normalization data did not resolve the detailed structure found in this study. Extremely rapid changes in VGP location have also been reported in Miocene lavas generated during the Steens Mountain polarity transition (Mankinen et al., 1985; Coe and Prevot, 1989). In addition, Clement and Kent (1991) have more recently derived a Brunhes/Matuyama reversal record from ocean sediments in the Southwestern Indian Ocean, whose change from positive to negative inclinations occurs over $1.9 \mathrm{~cm}$, equivalent to $<500 \mathrm{yr}$ from the average sedimentation rate of the relevant core interval. However their $180^{\circ}$ change in declination values was much more gradual, occurring over an interval of $\sim 30 \mathrm{~cm}(7,500 \mathrm{yr})$.

The oscillating behavior of the Leg 126 reversal remanence intensities, which is especially evident in the XYZ component plot of Figure $1 \mathrm{~B}$, is the second striking feature of the Leg 126 reversal records. The similarity in the number and relative spacing of the normalized intensity peaks for Holes 791B and 792A (Figs. 7A and 7B) supports the fidelity of these data, particularly as these two holes were drilled in different sedimentary basins. The presence of all the major intensity cycles in Hole 791B, with perhaps only a part of Peak \#2 missing, suggests that the reversal record is nearly as complete as in Hole 792A, even though $>10 \mathrm{~m}$ were lost from recovery somewhere within the depth intervals represented by the Hole 791B cores shown in Figure 7A.

Sample 126-792A-7H-2, 42-44 cm (Number 5 in Fig. 5), was the only specimen taken from a light colored layer extending from 40 to $50 \mathrm{~cm}$ in Section 126-792A-7H-2 (Fig. 8). Although its demagnetized NRM value is among the highest in intensity, its ARM and IRM intensities are several times lower than all other samples in the sequence. As a consequence, its resultant normalized NRM values are by far the highest among the measured Hole 792A specimens (Table 
A.

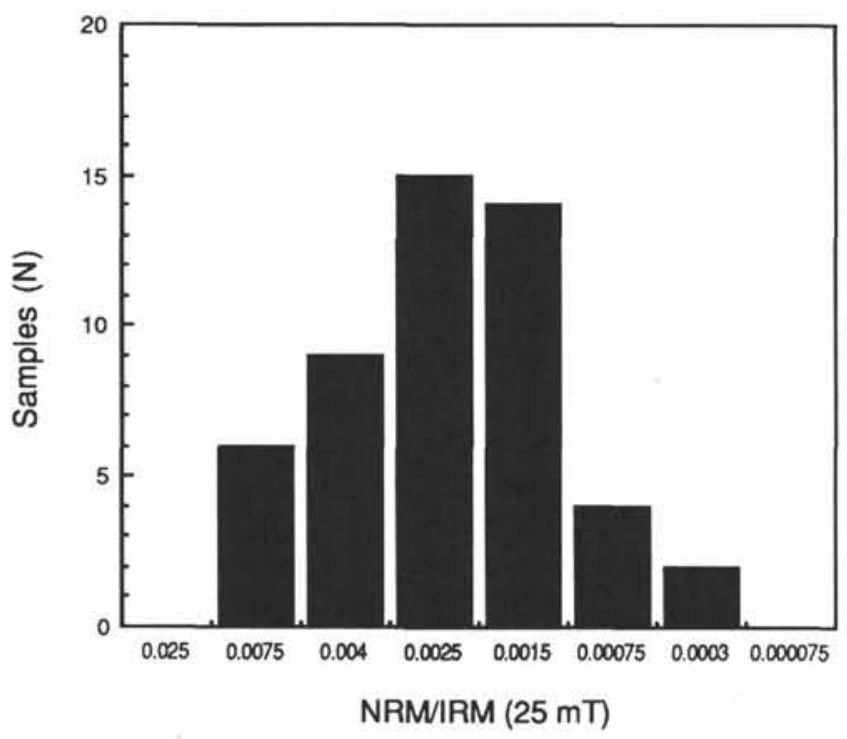

B.

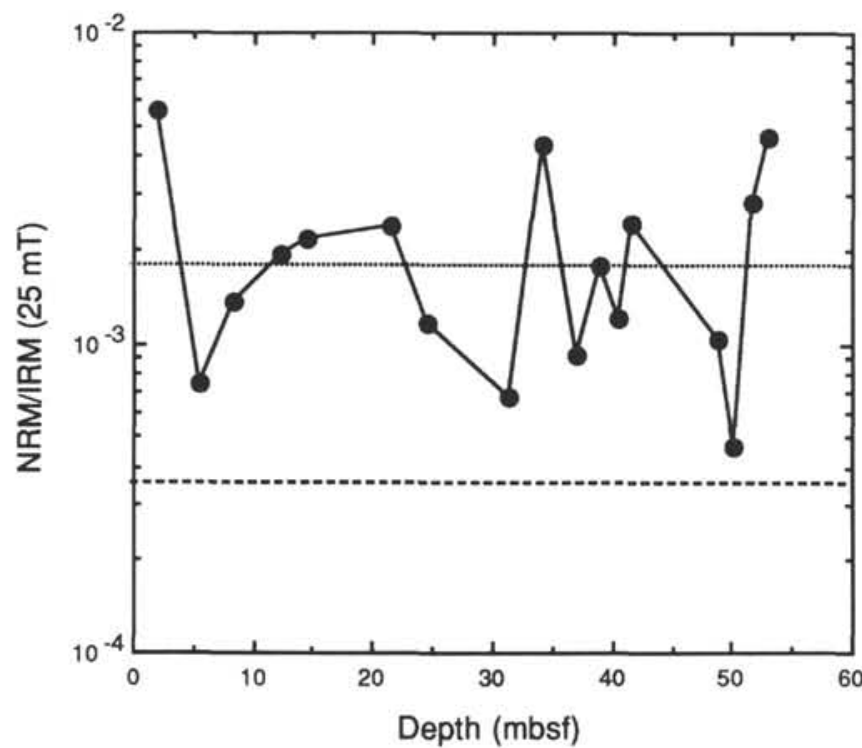

Figure 6. A. Bar graph illustrating the distribution of the ratio NRM/IRM, computed after $\mathrm{AF}$ demagnetization to $25 \mathrm{mT}$, for 50 clay and silt samples taken from above the Brunhes/Matuyama reversal at Sites 790-793. Values printed on the horizontal axis are midpoint values for the ratio ranges by which the samples are grouped. IRM was acquired in a field of $600 \mathrm{mT}$. B. The NRM/IRM ratios, after demagnetization, vs. depth for 17 normal samples taken at random from above the Brunhes/Matuyama reversal in Hole 792A. Dotted line indicates median ratio value for these samples. Dashed line indicates median ratio value for samples from the polarity reversal zone in Hole 792A (Table 1).

1). Figure $9 \mathrm{~A}$ shows that this sample has extreme directional stability with $\mathrm{AF}$ demagnetization, with a linear approach to the origin on the orthogonal component diagram. This behavior is indicative of a lack of any significant secondary component of magnetization. In contrast, the demagnetization behavior of nearby Sample 126-792A-7H-7, $52-54 \mathrm{~cm}$ indicates the removal of a large secondary component with a direction that approximates that of the present field (Fig. 9B). This secondary component almost certainly represents either a viscous remanent magnetization (VRM) acquired by the sample through time, since the polarity reversal, or a remanence acquired during drilling.

This contrast in directional response to $\mathrm{AF}$ demagnetization confirms that the more than an order of magnitude change in normalized NRM parameters between these two samples is a reflection of a significant change in paleofield intensity. The AF response of the two samples can be thought of in terms of a "signal-to-noise" analogy, with the primary reversed component as the signal, and the overlying normal present-field component as the noise. Clearly, the signal-tonoise ratio in Sample 126-792A-7H, 42-44 cm, is much higher than that of the stratigraphically lower sample. The most direct explanation for this contrast is that the "signal" of the younger sample was acquired when the geomagnetic field strength was strong. This sample's high VGP latitude $\left(88.6^{\circ} \mathrm{S}\right)$ (Fig. 7C), also supports the inference that a strong uniaxial dipole component dominated the geomagnetic field while the sample acquired its remanence.

The contrast in the NRM intensity response of these two samples also reflects their different signal-to-noise ratios. An initially resistant (Fig. 9A) or increasing intensity response (Fig. 2), with little or no rotation of the field vector direction, we label as Type A behavior. This response is characteristic of reversed samples with high NRM/ARM and NRM/IRM values (Table 1). Reversed samples with lower normalized NRM ratios have initially low resistance to AF demagnetization and show significant rotation of their field vector away from either the present field direction or a vertical (drill stem remanence?) direction, and toward a primary reversed direction (Fig. 9B). Figures 2 and $3 \mathrm{~A}$ provide an additional contrast between these two classes of AF demagnetization response.

To test whether a systematic difference in coercivity spectra can explain the behavior of the Type A (strong normalized intensity) and Type B (weak normalized intensity) samples, we performed detailed $A R M$ and IRM acquisition and AF demagnetization on representative samples. Figures $10 \mathrm{~A}$ and $10 \mathrm{~B}$ reveal that, although variations exist between individual samples, no systematic differences are apparent in the coercivity spectra of the two types of sample. The IRM acquisition curves and resistant IRM and ARM demagnetization curves which resulted from these experiments further indicate that the Hole 792 A clay samples are dominated by fine magnetic grain, with remanent coercive force values in the range of $40 \mathrm{mT}$.

Figure 10C illustrates the near linear correlation between ARM acquisition and low field susceptibility for the samples from the Hole $792 \mathrm{~A}$ reversal interval, which indicates a uniform magnetic grain size distribution for the samples. A 20 times variation in the concentration of magnetic carriers, from least magnetic Sample 126-792A-7H-2, 42-44 $\mathrm{cm}$, is indicated by the range in ARM intensity and susceptibility values. Principal Curie temperatures, as determined by thermal demagnetization of high field IRM, range from $\sim 450^{\circ}$ to $590^{\circ} \mathrm{C}$ for samples from Holes 790C, 791B, and 792A. This indicates "moderate to low Ti-content" titanomagnetite as the primary magnetic carrier, a result consistent with the high remanence intensities associated with these sediments (Table 1). The similarity of these sediment Curie temperatures to those of Quaternary extrusive rocks from the nearby Izu Peninsula (Kikawa et al., 1989), further supports a detrital origin for the sediment magnetite, as derived from nearby volcanic arc islands.

All the above rock magnetic data serve to satisfy the criteria of King et al. (1983) for identifying sediments suitable for paleointensity studies via the ARM normalization technique. This further justifies our interpretation of the variations in archive core (Fig. 1B) and discrete sample intensity (Figs. 7A and 7B) as reflections of true oscillations in geomagnetic intensity immediately before the polarity reversal.

Furthermore, the fine structure in our normalized intensity data appears to be in qualitative agreement with relative paleointensity data recently acquired by Clement and Kent (1991) for the Southern Hemisphere core (V16-58) discussed above which displayed a rapid inclination sign change. Figure 11, which was constructed by matching intensity peaks from the records of Hole 792A and its nearantipodal counterpart, and then interpolating for the depths of the 
A.
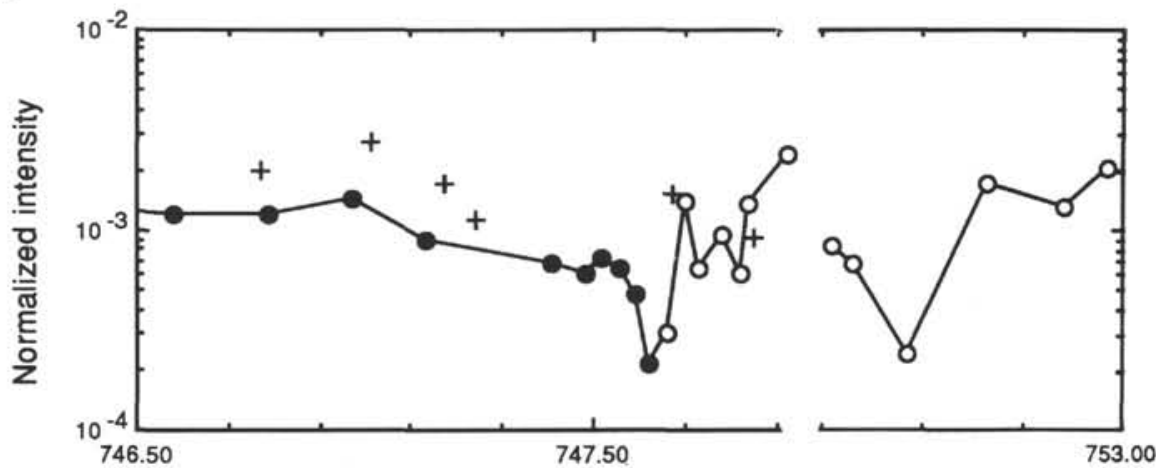

B.

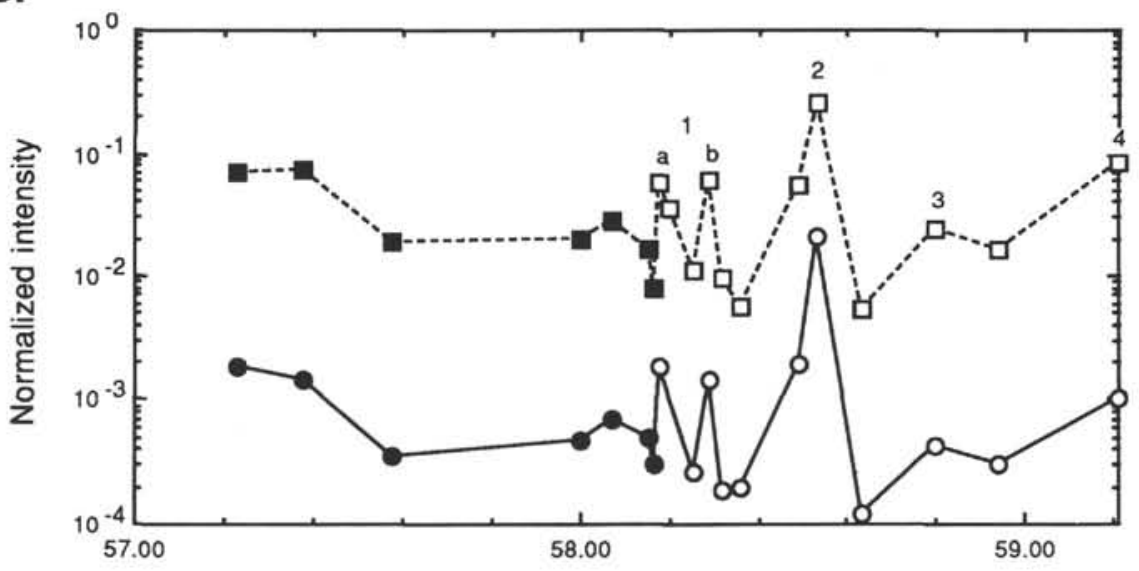

C.



Figure 7. A. Normalized intensity (NRM/IRM) vs. depth for discrete samples from Sections 126-791B38R-3, -4 and $-\mathrm{CC}$, and Section 126-791B-39R-1. Solid circles $=$ normal samples and open circles $=$ reversed samples. The break in the depth axis at $\sim 747.7 \mathrm{mbsf}$ corresponds to the bottom of Core $38 \mathrm{R}$. Crosses $=$ samples from Sections 126-790C-17X-7 and -CC that have been plotted on the Hole 791B depth scale by measuring their distance from the reversal plane, after adjustment for difference in the average sedimentation rates. B. Normalized intensities (squares $=$ NRM/ARM, circles $=N R M / I R M$ ) vs. depth for samples from Cores 126-792A-7H-1 and -2. Intensity peaks are numbered to help in the comparison with Figure 1. C. VGP latitude vs. depth for the same samples. Small triangles connected by dotted lines = VGPs after AF demagnetization to $25 \mathrm{mT}$ only. 


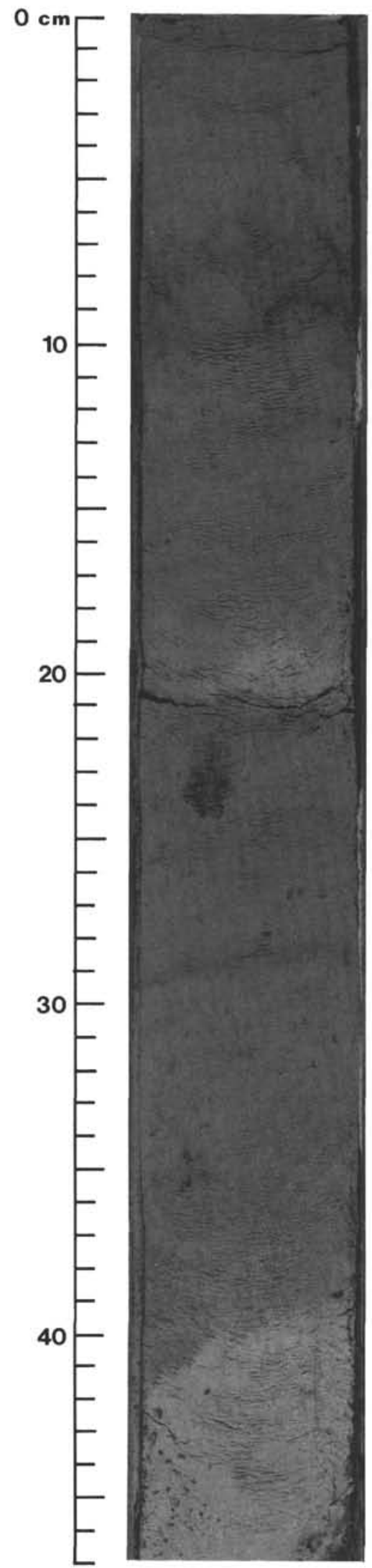

Figure 8. Core photograph of the top portion of Section 126-792A-7H-2, 1-47 $\mathrm{cm}$. The Brunhes/Matuyama polarity reversal occurs at a depth of $6-7 \mathrm{~cm}$ in this core section. additional Core V16-58 data points, indicates a remarkable similarity in intensity behavior preceding the polarity reversal. However for the correlation to be real, the true accumulation rate during the reversal interval of Hole 792A would have to be $\sim 10$ times greater than the indicated rate of the Southern Hemisphere core $(40 \mathrm{~m} / \mathrm{m}$.y.). While this is about 5 times greater than the estimated rate for the relevant portion of Hole $792 \mathrm{~A}$, it is within $35 \%$ of the estimated accumulation rate of Hole 791B, which has a similar reversal zone depth interval to Hole 792A (Figs. 7A and 7B).

If these records are true representations of transitional field behavior, they indicate that the geomagnetic field behaves much as a self-generating coupled disk dynamo, as modeled by Cook and Roberts (1970). That is, the polarity reversal takes place during the last trough in a series of intensity oscillations of large magnitude, as the intensity of the field approaches zero. The Leg 126 data differs from the pre-reversal field intensity pattern derived from the Rikitake dynamo model (Rikitake and Honkura, 1985) in that the intensity oscillation with the greatest amplitude (i.e., Peak \#2 in Figs. 7A) occurs in the third cycle, rather than immediately before, the VGP reversal.

Why our reversal records and those of the nearby Boso Peninsula indicate that the magnetic pole resided in moderate to high southern latitudes for most of the anomalous intensity period, while most other sedimentary reversal records include an abundance of low latitude VGPs (Fuller et al., 1979), remains a matter of conjecture. As stated above, the magnetic remanence for the Leg 126 and Boso Peninsula records appears to reside within detrital grains derived from their volcanic arc environments. In our study, the use of the continuous (high-temperature) thermal demagnetization technique proved a necessary means of removing normal inclination overprints, particularly for samples from Hole 790C. Thus, the technique served to eliminate low-latitude VGPs that would have been extant had only AF demagnetization been employed (Fig. 7C).

Rochette (1990) recently postulated that low sedimentation rate reversal records, particularly when authigenic magnetic minerals are present, are likely to reflect a mixture of nonantipodal normal and reversed components in each sample. This homogenization of the reversal record, which would also result in low normalized remanence intensities, results if an extended period of remanence acquisition occurs for each sample. The effect would be a severe convolution of the true temporal geomagnetic field record with the remanence acquisition function of the sediment, resulting in a highly smoothed record. Perhaps because of the combination of high sedimentation rate and a high input of detrital magnetic grains, the Leg 126 and Boso Peninsula records appear to have escaped more of this degradation effect than many other sedimentary records.

Although the field appears to retain its dipolar configuration throughout most of our reversal record, especially during the intensity peaks, we observed limited evidence that higher order terms may dominate geomagnetic reversal behavior during short intervals. The effect of quadrupole, octupole, and other zonal configurations as important contributors to the geomagnetic field is to cause the VGP to migrate through (high positive inclination), or antipodal to (high negative inclination) the site (Weeks et al., 1988). Such behavior is seen above the reversal horizon at a depth of $26 \mathrm{~cm}$ in Section 126-790C-17X-7 and at $17 \mathrm{~cm}$ in Section 126-791B-38R-4 (Taylor, Fujioka, et al., 1990, "Sites 790/791" chapter, fig. 50), and below the reversal horizon at $56 \mathrm{~cm}$ and again at $80 \mathrm{~cm}$ in Core 126-792A-7H (Fig. 1A).

Measurement of a discrete sample taken from 25 to $27 \mathrm{~cm}$ in Core 126-790C-17X-7 confirmed a high, positive inclination with high stability to AF demagnetization. However, as seen in Figure 5, none of the VGPs derived from the Hole 792A discrete samples, including Samples 126-792A-7H-2, 52-54 cm and $83-85 \mathrm{~cm}$, fall near the sampling site $(+)$ or its antipode in the Southern Hemisphere.

Laj et al. $(1987,1990)$ have also noted very fast north to south directional changes, episodes of collapse and recovery of field intensity, and a preponderance of North American VGP paths for a series 

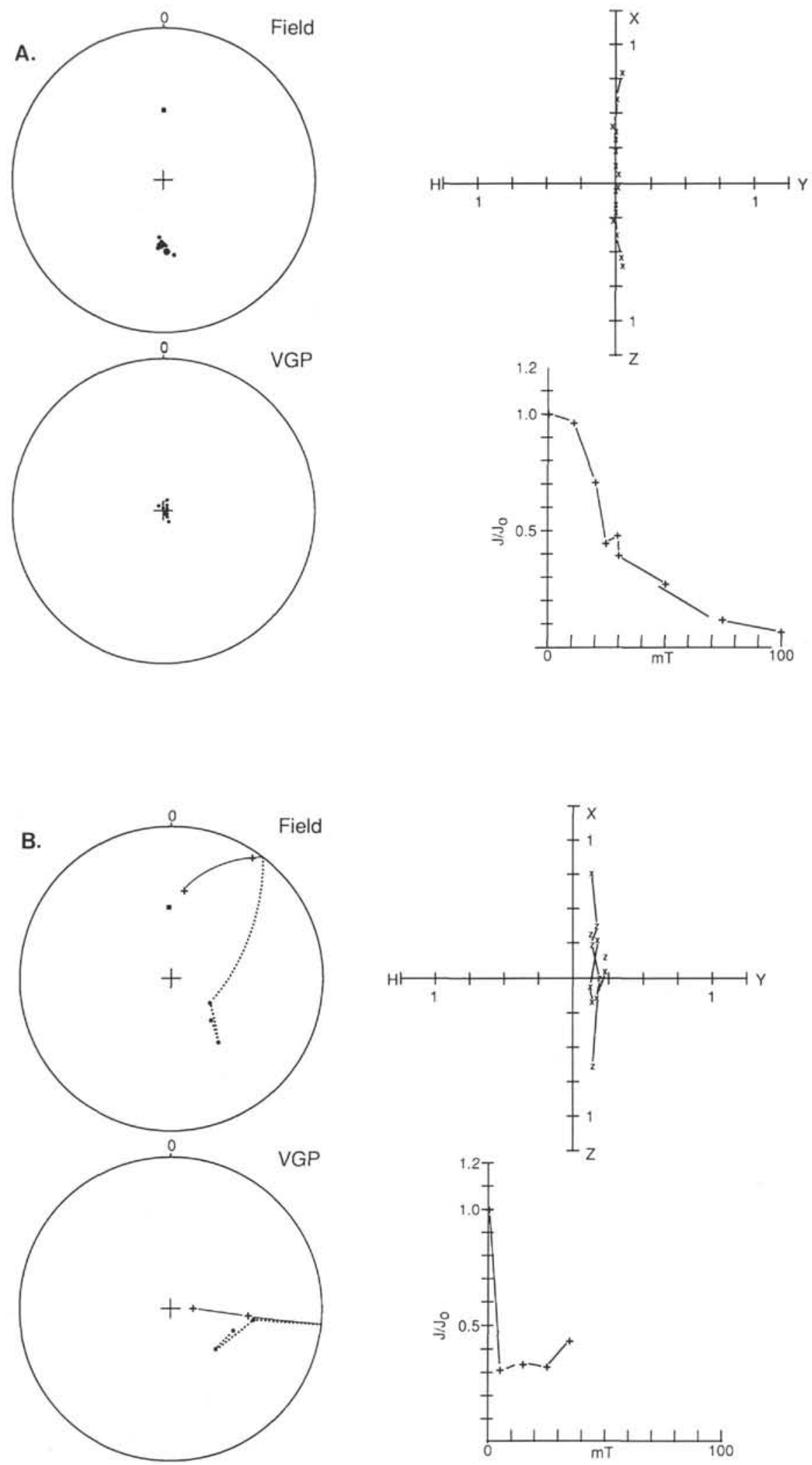

Figure 9. A. Response of Sample 126-792A-7H-2, 42-44 cm, to AF demagnetization. Labeling is the same as Figure 2. B. Same for Sample 126-792A-7H-2, 52-54 cm. 
A.

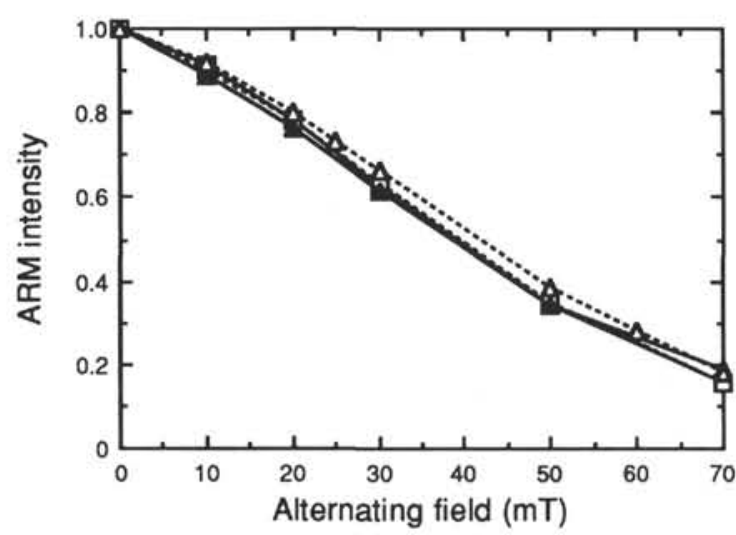

B.
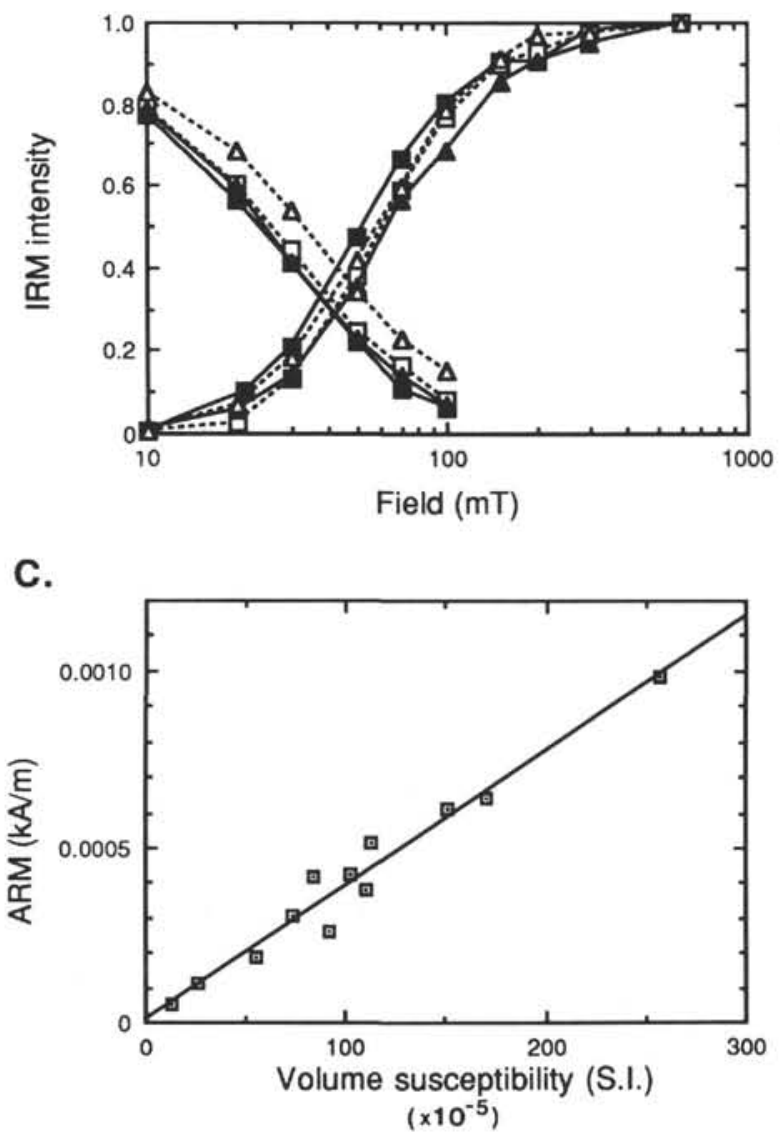

Figure 10. A. Response of ARM to AF demagnetization for four samples from the Brunhes/Matuyama reversal interval in Hole 792A. Solid square $=$ Sample 126-792A-7H-2, 7-9 cm. Open square $=$ Sample $126-792 \mathrm{~A}-7 \mathrm{H}-2,12-14 \mathrm{~cm}$. Solid triangle $=$ Sample $126-792 \mathrm{~A}-7 \mathrm{H}-2,18-20 \mathrm{~cm}$. Open triangle $=$ Sample $126-792 \mathrm{~A}-7 \mathrm{H}-2,25-27 \mathrm{~cm}$. Samples that possess strong normalized intensities (Type A behavior) are identified by solid lines. Samples that possess weak normalized intensities (Type B behavior) are identified by dashed lines. B. Acquisition and AF demagnetization of IRM for the same samples. C. ARM vs. weak field susceptibility, with least-squares correlation line, for samples included in Table 1. of middle Miocene reversals. These observations imply the continuance of a dipole field component even during the period of inclination sign change. Although the Hole 792A VGP reversal path, based on only two data points, does support a North American pole path, the extremely limited number of low-latitude VGPs in our study restricts the significance of this finding. In contrast, the VGP path derived from Boso Peninsula study travels through the site (Okada and Niitsuma, 1989, fig. 11). At this time we do not have an explanation as to why two sites only a few hundred kilometers apart produced such different reversal VGP paths.

\section{CONCLUSIONS}

The high sedimentation rate reversal records for the Brunhes/Matuyama obtained from the Leg 126 cores suggest that the reversal of VGP polarity is a fast phenomenon, ranging from $100 \mathrm{yr}$ for the migration of the pole from moderately high southern to moderately high northern latitudes, to only tens to hundreds of years for the equatorial crossing of the VGP. However, the time interval of VGP migration appears to be preceded by a period of thousands of years during which the dipole field undergoes extreme oscillations in intensity. The reversal then takes place during a final intensity low, perhaps while the field has decayed to nearly zero. As such, the reversal behavior recorded in the Leg 126 cores mimics the intensity behavior of self-reversing, coupled-disk dynamos and suggests that the geomagnetic reversal process is not causal, but instead is more characteristic of chaotic behavior.

The irregular cyclical intensity pattern derived from the Leg 126 cores also suggests that each geomagnetic reversal may have some unique field-intensity behavior (e.g., number, period, and amplitude of intensity cycles before the reversal) that would allow for chronological identification based on intensity pattern alone. For instance, detailed absolute paleointensity data from lava flows extruded during a Miocene polarity transition also show large dipole field intensity oscillations, which, in contrast to this study, primarily occur after the polarity transition (Prevot et al., 1985). However, additional highresolution records of this and previous reversals, are required to further test this proposition.

\section{ACKNOWLEDGMENTS}

We thank N. Niitsuma and C. Laj for their suggestions and constructive criticisms arising from their reviews of this manuscript, R. Weeks and M. Fuller for their comments and suggestions, J. R. Dunn for laboratory assistance, B. Clement for the use of his paleointensity data, and D. Crouch for his drafting expertise. This research was funded by a National Science Foundation Grant through a subcontract to the Texas A\&M Research Foundation.

\section{REFERENCES}

Clement, B. M., and Kent, D. V., 1991. A Southern Hemisphere record of the Matuyama-Brunhes polarity reversal. Geophys. Res. Lett., 18:81-84.

Coe, R. S., and Prevot, M., 1989. Evidence suggesting extremely rapid field variation during a geomagnetic reversal. Earth Planet. Sci. Lett., 92:292-298.

Cook, A. E., and Roberts, P. H., 1970. The Rikitake two-disk dynamo system. Math Proc. Cambridge Philos. Soc., 68:547-569.

Fuller, M., Williams, I., and Hoffman, K. A., 1979. Paleomagnetic records of geomagnetic field reversals and the morphology of the transitional fields. Rev. Geophys. Space Phys., 17:179-203.

Kikawa, E., Koyama, M., and Kinoshita, H., 1989. Paleomagnetism of Quaternary volcanics in the Izu Peninsula and adjacent areas, Japan, and its tectonic significance. J. Geomagn. Geoelectr., 41:175-201. 


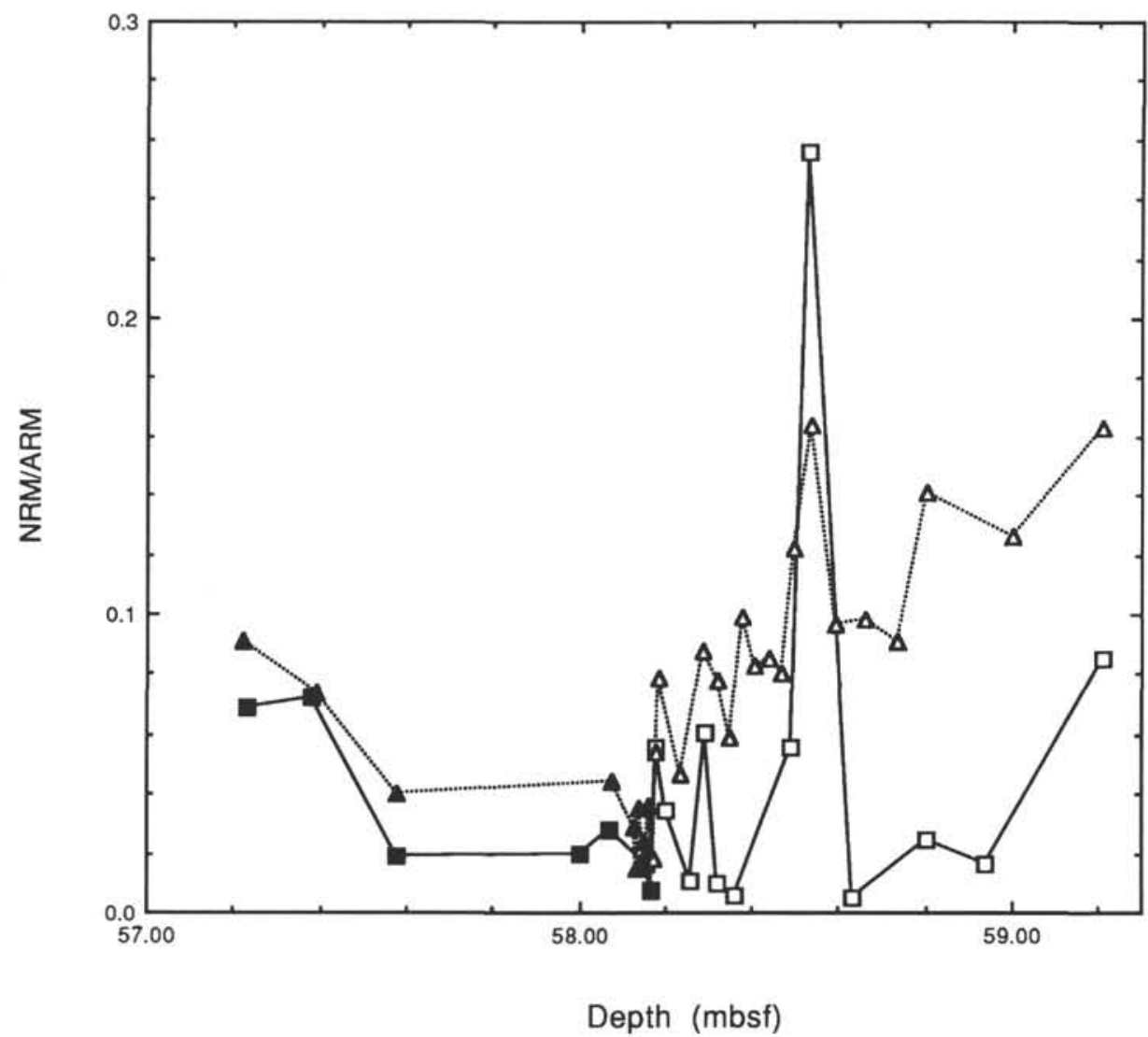

Figure 11. A linear plot of NRM/ARM ratio (after AF demagnetization) vs. depth for samples that define the Brunhes/Matuyama reversal in Hole 792A (squares) and in Lamont-Doherty Core V16-58 (triangles = Clement and Kent, 1991). Depths for the Core V16-58 samples were assigned by matching intensity peaks with the Hole 792A samples (see text). Only representative Core V16-58 samples from above the inclination sign change horizon are included from the Clement and Kent data set.

King, J. W., Banerjee, S. K., and Marvin, J., 1983. A new rock-magnetic approach to selecting sediments for geomagnetic paleointensity studies: application to paleointensity for the last 4000 years. J. Geophys. Res., 88:5911-5921.

Laj, C., Guitton, S., and Kissel, C., 1987. Rapid changes and near-stationarity of the geomagnetic field during a polarity reversal. Nature, 330:145-148.

Laj, C., Mazaud, A., Tric, E., Fuller, M., Ruocco, M., and Herrero-Bervera, E., 1990. Geomagnetic reversals, core surface fields and motion, and thermal anomalies in the mantle and at the core-mantle boundary. Eos, 71:1286. (Abstract)

Mankinen, E. A., Prevot, M., Gromme, C. S., and Coe, R. S., 1985. The Steens Mountain geomagnetic polarity transition. I. Directional history, duration of episodes, and rock magnetism. J. Geophys. Res., 90:10,379-10,417.

Okada, M., and Niitsuma, N., 1989. Detailed paleomagnetic records during the Brunhes-Matuyama geomagnetic reversal, and a direct determination of depth lag for magnetization in marine sediments. Phys. Earth Planet. Int., 56:133-150.

Prevot, M., Mankinen, E. A., Coe, R. S., and Gromme, C. S., 1985. The Steens Mountain (Oregon) geomagnetic polarity transition. 2. Field intensity variations and discussion of reversal models. J. Geophys. Res., 90:10,41710,448 .

Rikitake, T., and Honkura, Y., 1985. Solid Earth Geomagnetism: Tokyo (Terra Sci. Pub.).

Rochette, P., 1990. Rationale of geomagnetic reversals versus remanence recording processes in rocks: a critical review. Earth Planet. Sci. Lett., 98:33-39.

Taylor, B., Fujioka, K., et al., 1990. Proc. ODP, Init. Repts., 126: College Station, TX (Ocean Drilling Program).

Weeks, R. J., Fuller, M., and Williams, I., 1988. A model for transitional field geometries involving low-order zonals and drifting nondipole harmonics. J. Geophys. Res., 93:11,613-11,620.

Date of initial receipt: 16 November 1990

Date of acceptance: 29 May 1991

Ms 126B-142 